\title{
Immediate and long-term outcomes of percutaneous transcatheter pulmonary valve implantation
}

\author{
Roland Fiszer ${ }^{1}$, Paweł Dryżek ${ }^{2}$, Małgorzata Szkutnik ${ }^{1}$, \\ Sebastian Góreczny², Alexandra Krawczuk², Jadwiga Moll², \\ Tomasz Moszura ${ }^{2}$, Szymon Pawlak ${ }^{3}$, Jacek Białkowski ${ }^{1}$ \\ ${ }^{1}$ Department of Congenital Heart Diseases and Pediatric Cardiology, Silesian Center \\ for Heart Diseases, Silesian University of Medicine, Zabrze, Poland \\ ${ }^{2}$ Pediatric Cardiology Department of Polish Mother's Memorial Hospital, Łódź, Poland \\ ${ }^{3}$ Pediatric Cardiac Surgery, Heart Failure and Transplantation Department, \\ Silesian Center for Heart Diseases, Zabrze, Poland
}

\begin{abstract}
Background: Transcutaneous pulmonary valve replacement (TPVR) has become an alternative to heart surgery for patients after previous right ventricular outflow tract (RVOT) or pulmonary artery (PA) surgical interventions. The objective was to present immediate and long-term outcomes of transcutaneous pulmonary valve replacement.

Methods: Between 06/2009 and 06/2016, 46 patients underwent TPVR. Initial diagnoses included tetralogy of Fallot, common arterial trunk, transposition of great arteries post Rastelli correction, left ventricle outflow obstruction after Ross operation, pulmonary atresia, and isolated dysplastic pulmonary valve stenosis. Thirty eight (78\%) patients had previously implanted conduits in the pulmonary position, the rest had either $R V O T$ patch reconstruction $(n=6 ; 13 \%)$ or biological valve implantation $(n=2$; $4 \%)$. They presented primarily with pulmonary stenosis $(n=18 ; 39 \%)$ or regurgitation $(n=28 ; 60 \%)$. Results: All procedures were successful - 44 Melody and 2 Edwards-Sapien valves were implanted. Before each procedure exclusion of potential coronary compression and RVOT prestenting was performed. Significant RVOT systolic gradient reduction (from $35.3 \pm 19.5$ to $13.5 \pm 7.1 \mathrm{~mm} \mathrm{Hg} ; p<0.001$ ) and decrease of right to left ventricle systolic pressure ratio from $0.58 \pm 0.18$ to mean $0.37 \pm 0.1$ $(p<0.001)$ was achieved. Also, in every patient PA-RVOT competence was restored, with minor incompetence in only a few patients. Post procedure follow-up ranged from 2 to 86 (mean 35.2) months. Follow-up fluoroscopy or chest X-ray revealed 6 stent fractures (2 stent defragmentation - with only 1 significant valve stenosis).

Conclusions: Transcutaneous pulmonary valve replacement is a safe procedure with encouraging results, it also enables deferring surgical reintervention in the majority of patients. (Cardiol J 2017; 24, 6: 604-611)
\end{abstract}

Key words: pulmonary valve, transcatheter valve implantation, congenital heart disease

\section{Introduction}

Transcutaneous pulmonary valve replacement (TPVR) has become a promising alternative to open heart surgery for patients after previous right ven- tricular outflow tract (RVOT) or pulmonary valve and pulmonary artery (PA) surgical interventions. Initially, the treatment was limited to a select group of patients with a dysfunction (stenosis and/or insufficiency) of a previously implanted surgical

Address for correspondence: Roland Fiszer, MD, Department of Congenital Heart Diseases and Pediatric Cardiology, Silesian Center For Heart Diseases, Silesian University of Medicine, ul. Marii Curie-Skłodowskiej 9, 41-800 Zabrze, Poland, tel/fax: +48 3227134 01, e-mail: rfiszer@gumed.edu.pl

Received: 27.09.2016 Accepted: 05.01.2017 
graft. Mainly patients after surgery for tetralogy of Fallot (TOF) with homograft, pulmonary atresia, common arterial trunk, and patients after Ross and Rastelli operations were candidates for this method of treatment. Those patients usually had undergone several surgical interventions. The general indications for pulmonary valve replacement are well defined $[1,2]$ and rely on right ventricular (RV) enlargement and functional compromise, along with pulmonary artery stenosis and/or regurgitation. Both are preferentially presented on magnetic resonance imaging [3]. The number of patients undergoing transcatheter pulmonary valve implantation has been steadily increasing. Since 2000, when Bonhoeffer et al. [4] preformed the first human implantation, more than ten thousand procedures have been performed with favorable results. In the last few years the indications for TPVR expanded and the method of treatment has included some postsurgical patients after TOF repair with pericardial patch or biological valve in the pulmonary position. Moreover, an increasing number of publications on TPVR in non-standard pulmonary positions have been published $[5,6]$. Currently, there are two commercially available types of percutaneous implantable pulmonary valves on the European market, the more popular Melody valve (Medtronic Minneapolis, Minnesota, USA) and the less used Edwards-Sapien valve (Edwards Lifesciences LLC, Irvine, California, USA) [7, 8].

The aim of this study is to present 7 years of experience in percutaneous pulmonary valve implantation in patients with surgically placed conduits, or after RVOT patch repair performed at two reference centers in Poland.

\section{Methods}

Between 06/2009 and 06/2016, 46 patients had undergone TPVR in two tertiary centers. All met criteria to restore proper RV-PA function (RV diastolic volume index $>140 \mathrm{~mL} / \mathrm{m}^{2}$, RV end-systolic volume index $>80 \mathrm{~mL} / \mathrm{m}^{2}$ or pulmonary regurgitation fraction $>40 \%$ as well as RV function impairment - ejection fraction $<40 \%$ or RV-PA gradient $>40 \mathrm{~mm} \mathrm{Hg}$ ). There were $27(58 \%)$ males and $19(41 \%)$ females aged mean $18.3 \pm 6.9$ years. Their weight ranged from 28 to 98 , mean $55.5 \pm 15.8 \mathrm{~kg}$. Initial diagnoses included TOF $(\mathrm{n}=18 ; 39 \%)$, common arterial trunk $(\mathrm{n}=9$; $16 \%)$, transposition of great arteries post Rastelli surgery $(\mathrm{n}=8 ; 17 \%)$, aortic stenosis and left ventricular outflow tract obstruction post Ross-like operations $(n=5 ; 10 \%)$, pulmonary atresia $(n=3 ; 6 \%)$, and isolated pulmonary valve stenosis $(\mathrm{n}=2 ; 4 \%)$. Thirty eight $(82.6 \%)$ patients had had previously implanted conduits in the pulmonary position and presented clinically with significant graft narrowing and/or regurgitation. In the majority $(n=35 ; 92 \%)$ a homograft was used to reconstruct the RVOT, with the remaining received a contegra graft $(n=3$; $8 \%)$. Eight patients had either a patch reconstruction $(n=6)$ or biological valve implantation $(n=2)$. In $17(34 \%)$ stenosis (right ventricle - PA gradient $>40 \mathrm{~mm}$ ) and in $29(60 \%)$ regurgitation, was the major indication for TPVR. Among patients with predominant stenosis the RV-PA invasive systolic pressure gradient was mean $52.7 \pm 17.9 \mathrm{~mm} \mathrm{Hg}$, whereas in patients with predominant regurgitation the mean gradient was $24 \pm 9.9 \mathrm{~mm} \mathrm{Hg}$. Six patients with TOF had pericardial patch correction and presented with pulmonary regurgitation. One patient had a biological stentless valve (Freestyle $23 \mathrm{~mm}$ ) implanted in the pulmonary position, who shortly after surgery developed severe stenosis with an invasive gradient of $46 \mathrm{~mm} \mathrm{Hg}$. Another patient had TOF corrected with the application of the cor-matrix valve subsequently with a gradient of $52 \mathrm{~mm} \mathrm{Hg}$. Three TOF patients (two treated with homograft and one with cor-matrix valve) had a primary absent pulmonary valve with a grossly enlarged PA (one with left pulmonary artery agenesis). Similarly, two patients after homograft insertion had pulmonary artery agenesis, one left-sided and one right-sided.

All patients had diagnostic images including transthoracic echocardiogram, contrast computed tomography, magnetic resonance and/or diagnostic cardiac catheterization; in order to define stenosis and regurgitation and to determine anatomy for TPVR. All procedures were performed according to previously described methods [2, 5, 8-10]. General anesthesia with endotracheal intubation, antibiotic prophylaxis and intravenous heparin (100 IU/kg) were used in all patients. Diagnostic right heart catheterization was performed with angiography to define the RVOT physiology and anatomy. Potential coronary compression was excluded with simultaneous balloon inflation in the RVOT and selective coronary angiography or aortic root angiography. In adherence to the recommendations [7-9], all patients underwent routine prestenting to create a landing zone for subsequent TPVR. Two different types of implantable valves were used in the study. Melody valve - bovine jugular venous valve sutured on 8-zig, $34 \mathrm{~mm}$ Cheatham Platinum (CP) stent available in two diameters; expandable to $20 \mathrm{~mm}$ and to $22 \mathrm{~mm}$. The device was delivered on 18,20 , or $22 \mathrm{~mm}$ Ensemble delivery system. The 


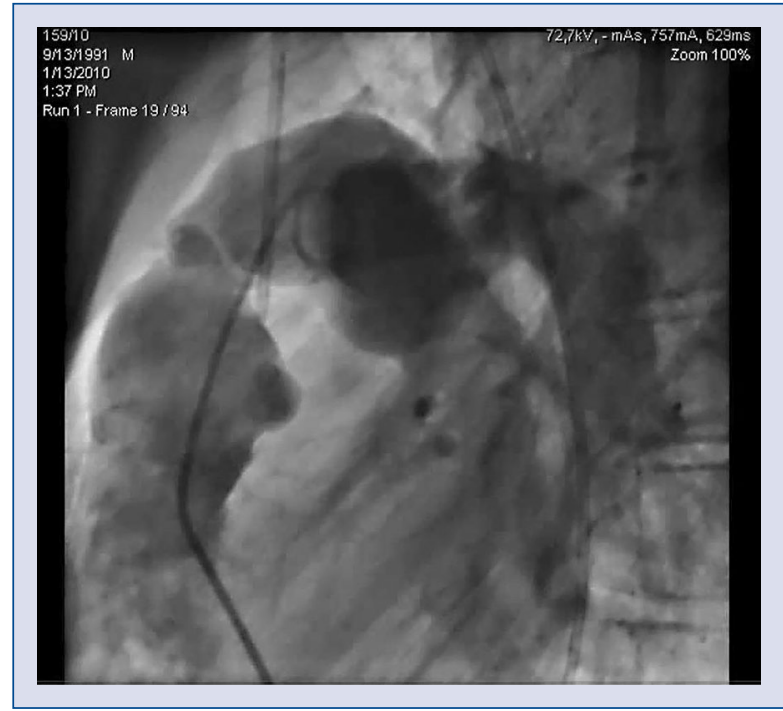

Figure 1. Pulmonary angiography in left anterior oblique (LAO) 90 projection. Homograft narrowing and severe pulmonary regurgitation.

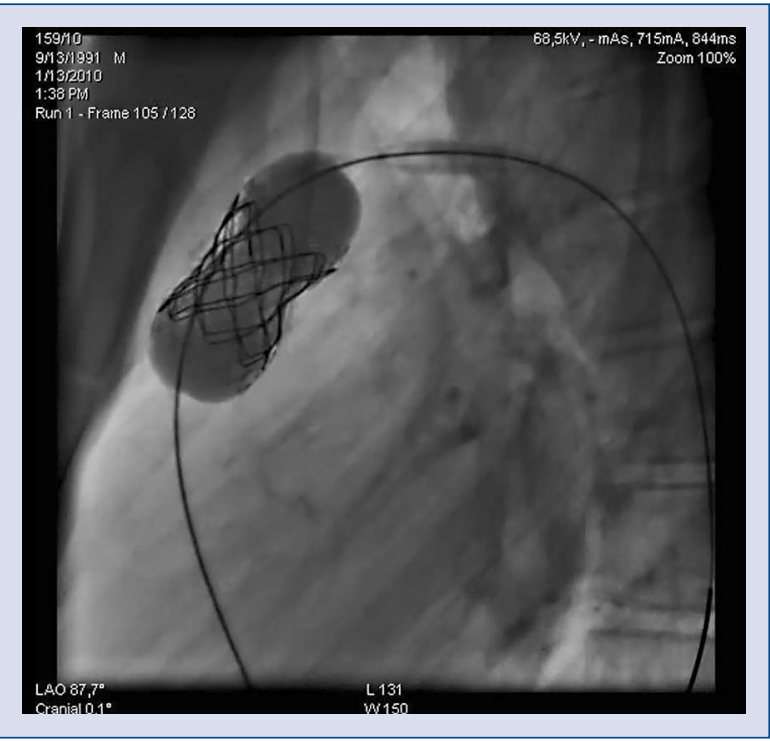

Figure 3. Left anterior oblique 90. Pulmonary valve expanded in presented right ventricular outflow tract.

Edwards-Sapien valve - bovine pericardial valve mounted within stainless steel stent is available in diameters of 23,26 and recently in $29 \mathrm{~mm}$ [8]. In 8 patients valve implantation was postponed for 2-3 months after prestenting in order to allow stent fixation. The Melody valve was mounted on a 18,20 or $22 \mathrm{~mm}$ delivery system. EdwardsSapien valves were delivered on the Retroflex 3 delivery system (Figs. 1-4). Additional dilatation, with Mullins balloon $(22 \mathrm{~mm})$, was performed in

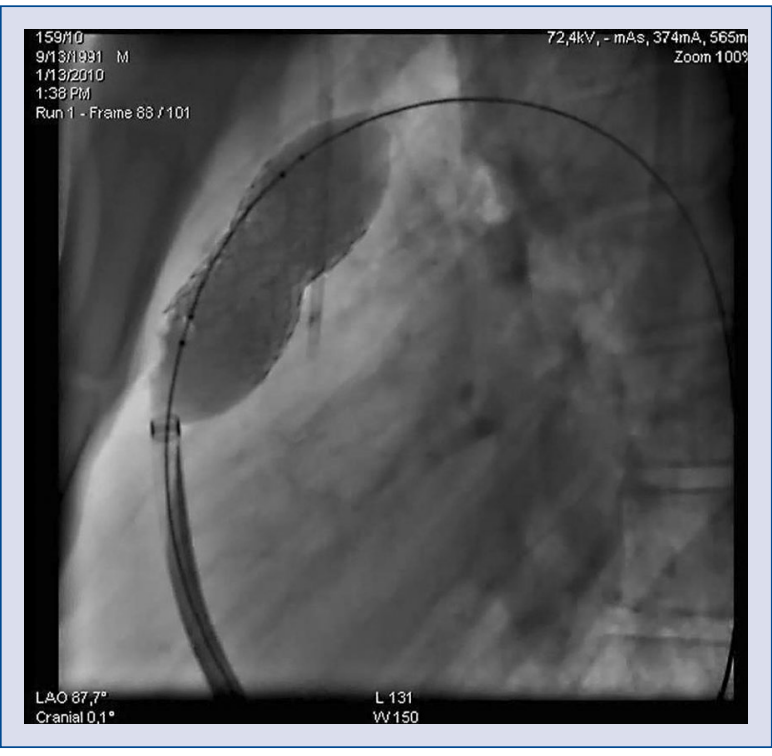

Figure 2. Left anterior oblique 90. Right ventricular outflow tract prestenting.

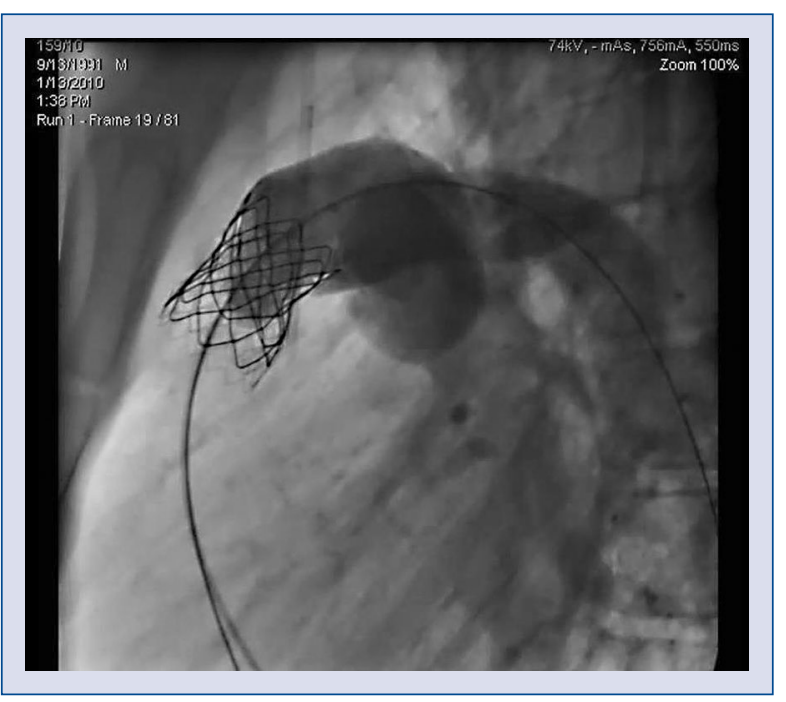

Figure 4. Pulmonary angiography left anterior oblique 90. Competent valve implanted in pulmonary position.

15 patients with $>25 \mathrm{~mm} \mathrm{Hg}$ gradients across the valve. Hemostasis was achieved with compression or Z-suture. Patient follow-up included clinical examination, electrocardiogram, transthoracic echocardiography and chest X- ray or fluoroscopy.

\section{Ethical considerations}

No ethical committee agreement was required. Each patient signed written consent for the procedure. 
Statistical analysis

Shapiro-Wilk test was used for testing normality. Depending on statistical distribution, numerical data were shown by mean and standard deviation, then compared with t-Student test for paired samples or Wilcoxon signed-rank test for in-time comparisons. The difference between groups was compared using t-Student for independent samples or the Mann-Whitney U test. Binary data were compared with the Yates corrected $\chi^{2}$ test. Kaplan-Meier curves were used to assess free-from-failure survival. $\mathrm{P}<0.05$ was considered significant.

\section{Results}

During the study all 46 patients underwent successful TPVR procedures, 44 patients with Melody valve and 2 patients with Edwards-Sapien valve. Most procedures were performed using the standard technique, from femoral access. In 2 patients with bilateral femoral vein occlusion the jugular approach was used, 1 patient required trans-atrial valve implantation. One with greatly enlarged RVOT, required the hybrid procedure with surgical narrowing initially, and then percutaneous valve implantation. All patients had routine prestenting — the majority of which $38(82 \%)$ during the same procedure. Five patients with TOF and pericardial patch had severely dilated RVOT - prestenting was performed in order to prevent further dilatation and to create the landing zone for TPVR 3 months before implantation. Also, 3 patients with full homograft had a prestenting procedure initially, and 3 months later, valve implantation. In one of those patients there was significant narrowing of the RVOT after double stent implantation, and immediately preceding the Melody valve another stent was implanted. One patient had the landing zone created in a telescopic manner utilizing the previously implanted stent in the left PA. In another patient with graft narrowing close to the bifurcation - the first stent was implanted partially into the right PA, stent struts were opened into the left PA and the next was implanted below. Prestenting procedures were performed with AndraStent in 20 (43\%) patients, bare CP stent in $14(30 \%)$, covered CP stent in $10(21 \%)$ and IntraStent in $2(4 \%)$ patients. Eight patients with severe homograft stenosis required multiple (2 or 3) stents due to significant stent recoil after balloon deflation. The $22 \mathrm{~mm}$ delivery system was utilized in 29 patients, $20 \mathrm{~mm}$ in 13 patients and $18 \mathrm{~mm}$ in 2 patients. Two patients received a $23 \mathrm{~mm}$ Edwards-Sapien valve (decision operator dependent).
TPVR was successful in all cases. The systolic pressure gradient decreased from mean $35.3 \pm 19.5$ $\mathrm{mm} \mathrm{Hg}$ to mean $13.5 \pm 7.1 \mathrm{~mm} \mathrm{Hg}(\mathrm{p}<0.001)$. The gradient reduction was particularly spectacular in patients with predominant stenosis. In this group $(\mathrm{n}=17)$ the implantation gradient decreased from mean $52.7 \pm 17.9 \mathrm{~mm} \mathrm{Hg}$ to mean $15.2 \pm 7 \mathrm{~mm}$ $\mathrm{Hg}$ after the procedure. In the group with dominant regurgitation the gradient dropped from mean $24 \pm 9.9 \mathrm{~mm} \mathrm{Hg}$ to mean $12.5 \pm 7.1 \mathrm{~mm} \mathrm{Hg}$. The $\mathrm{RV} / \mathrm{LV}$ systolic pressure ratio before the implantation mean $0.58 \pm 0.18$ decreased to mean $0.37 \pm 0.1$ ( $\mathrm{p}<0.001$ ); from mean $0.7 \pm 0.18$ to mean $0.37 \pm$ \pm 0.08 among patients with predominant stenosis, and from mean $0.5 \pm 0.12$ to mean $0.37 \pm 0.11$ in those with significant regurgitation.

Selected demographic, procedural and follow-up data in both groups of patients are presented in Table 1.Initial systolic RV-PA gradientand RV/LV ratio before the procedure were significantly higher in patients with predominant stenosis $(\mathrm{p}<0.001)$.

One patient with critical homograft stenosis required serial dilatation with increasing balloon sizes followed by CP stent implantation and finally Melody valve insertion 3 months later. In angiography trivial post-procedural pulmonary regurgitation was observed in 7 patients after Melody valve implantation. Mild regurgitation was seen in both patients after Edwards-Sapien valve and one after Melody valve placement. Fifteen (32\%) patients required valve dilation with $22 \mathrm{~mm}$ high pressure Mullins balloon. No major procedural complications were observed. In 1 patient with TOF and absent pulmonary valve with enormously dilated PA treated with homograft, the stent used in the prestenting procedure dislocated distally. The stent was placed in the right PA and another one was successfully deployed. In 1 patient the tip of the guide wire was caught in the peripheral PA branch and could not be retrieved. The tip of the wire was cut off and left with no further consequences for the patient in follow-up. Mean post procedure follow-up was $35.2 \pm 28.9$ months. On first transthoracic echocardiography after the TPVR, 15 patients presented with trivial/mild regurgitation. During the followup no increase of pulmonary regurgitation was observed. RVOT peak gradient pre-discharge ranged from 7 to 47, mean $27 \pm 9.1 \mathrm{~mm} \mathrm{Hg}$. After a median of 35.2 months following the intervention the gradient ranged from 14 to 80 , mean $28 \pm 13.9 \mathrm{~mm} \mathrm{Hg}$. Stent integrity was assessed in $36(78 \%)$ patients either with fluoroscopy $(n=20)$ or with chest X-ray $(\mathrm{n}=16)$. Eight patients had the procedure performed less than 1 year before the end of follow-up 
Table 1. Some demographic procedural and follow-up data.

\begin{tabular}{|c|c|c|c|c|}
\hline Data & $\begin{array}{l}\text { Overall } \\
(n=46)\end{array}$ & $\begin{array}{l}\text { Predominant } \\
\text { stenosis }\end{array}$ & $\begin{array}{l}\text { Predominant } \\
\text { regurgitation }\end{array}$ & $\mathbf{P}$ \\
\hline Tetralogy of Fallot patients & 18 & 6 & 12 & 0.739 \\
\hline Other heart diseases & 28 & 11 & 17 & 0.979 \\
\hline \multicolumn{5}{|l|}{ Initial surgery } \\
\hline With conduit & 40 & 17 & 23 & 0.380 \\
\hline Without conduit & 6 & 0 & 6 & 0.068 \\
\hline Initial systolic RV-PA gradient [mm Hg] & $35.2 \pm 19.5$ & $55.18 \pm 14.98$ & $23.55 \pm 9.98$ & $<0.001$ \\
\hline Initial RV-Ao pressure ratio & $0.58 \pm 0.18$ & $0.71 \pm 0.19$ & $0.50 \pm 0.12$ & $<0.001$ \\
\hline Systolic RV-PA gradient post procedure [mm Hg] & $13.54 \pm 7.08$ & $15.77 \pm 6.77$ & $12.24 \pm 7.04$ & 0.085 \\
\hline Systolic RV-Ao ratio post procedure & $0.37 \pm 0.09$ & $0.38 \pm 0.07$ & $0.37 \pm 0.11$ & 0.829 \\
\hline Stents used in prestenting [no. of patients] & 56 & 25 & 31 & \\
\hline Complications & 2 & 0 & 2 & 0.524 \\
\hline Follow up [months] & $35.18 \pm 28.87$ & $38.88 \pm 30.67$ & $33.01 \pm 28.09$ & 0.682 \\
\hline \multicolumn{5}{|l|}{ Outcome } \\
\hline $\begin{array}{l}\text { Peak RV-PA gradient in echocardiogram } \\
\text { on discharge }[\mathrm{mm} \mathrm{Hg}]\end{array}$ & $27 \pm 9.12$ & $28 \pm 9.62$ & $27.30 \pm 9.75$ & 0.812 \\
\hline Stent integrity assessment (stent fracture) & $36(6)$ & $11(3)$ & $25(3)$ & 0.343 \\
\hline $\begin{array}{l}\text { Peak RV-PA gradient in echocardiogram } \\
\text { in last follow up [mm } \mathrm{Hg}]\end{array}$ & $28 \pm 13.89$ & $28 \pm 17.38$ & $28.51 \pm 10.79$ & 0.902 \\
\hline
\end{tabular}

RV — right ventricle; PA — pulmonary artery; Ao — aorta

and had no fluoro/X-ray checkup. In 1 patient fluoroscopy was abandoned due to pregnancy and 1 patient was lost from the follow-up. We found stent fracture in 4 and stent disintegrity in 2 patients with part of the stent embolized to the peripheral PA. Albeit there was no serious valve dysfunction in any patient with stent fracture or disintegrity. Only 1 patient presented with increase in RVOT peak gradient to $80 \mathrm{~mm} \mathrm{Hg}$ and is regarded as suitable for revalvulation. Follow-up data was used to build a Kaplan-Meier curve assessing free-from-failure with combined end-point: stent breakage and/or device dysfunction survival (Fig. 5).

\section{Discussion}

Surgical treatment of RVOT has been performed successfully by homograft insertion for many decades. Eventually however, a significant number of patients develop dysfunction often requiring re-intervention $[11,12]$. The patients are teenagers or young adults, often after several previous surgical interventions. TPVR has become an alternative method of treatment for those with residual stenosis or regurgitation [2, 10, 13-15]. Critically, this treatment is also possible for patients after TOF patch surgery, a large group of patients with congenital heart diseases. Patients

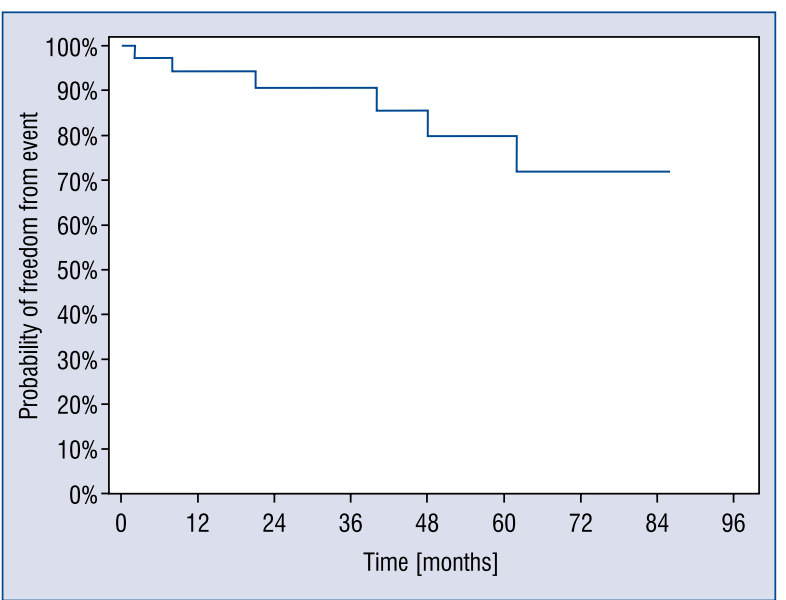

Figure 5. Kaplan-Meier curve depicting the probability of outcome - freedom from event (stent fracture and valve dysfunction) after transcutaneous pulmonary valve implantation.

at risk of coronary artery compression were excluded from the procedure [16-18]. Standard indications for TPVR require circumferential conduit in the pulmonary position. It was considered from experience that there were 35 patients with homografts, all were treated in the standard TPVR manner. According to recommendations, all had 
prestenting performed before TPVR. Prestenting decreases the number of stent fractures observed in follow-up [8, 19]. However, some authors [20] point out possible valve compression in significant homograft calcifications even with standard presenting. Eight patients in this study with tortuous conduits positioned close to the chest wall or with a tight stenosis, required multiple stents to create an unobstructed outflow tract. This approach may prevent the recoil phenomenon and subsequent valve compression. Those patients sometimes present increased RVOT gradient in follow-up and require valve replacement due to unacceptable residual stenosis. In order to prevent this situation, it was decided to separate prestenting and TPVR in 3 patient with homograft and tight stenosis. One patient underwent another stent implantation (3 months later) directly before the Melody valve was implanted. Also a few patients who required multiple balloon predilations of the RV-PA conduit to enable safe and effective prestenting.

Currently, a circumferential graft in the pulmonary position is not required for TPVR $[14,15$, 17]. In the present study, we had 6 patients with the RVOT reconstructed with a pericardial patch. This technique is used much more often for TOF correction than graft implantation. TPVR in such patients is possible, however, a staged approach with stent implantation followed by valve implantation 3 months later is preferred. This allows stent ingrowth, creating a stabile landing zone for subsequent valve placement. The delayed valve implantation in such patients is recommended by several authors $[7,8,21]$. One patient with severely dilated RVOT had surgical narrowing of the RVOT and then percutaneous valve implantation. This approach, to restore proper RV-PA function was done without cardio pulmonary by-pass. Many authors indicate pulmonary outflow diameter in patients with patch as the major limitation for TPVR $[7,8$, $15,17]$. The final decision was based on outflow tract balloon measurement during cardiac catheterization. For the Melody valve, stabile position of the balloon inflated in the RVOT with maximal diameter of the waist $\leq 25 \mathrm{~mm}$ are mandatory. One of the patched patients previously underwent a left PA stent implantation. The prestenting procedure was performed in a telescopic manner, with a left PA stent serving as an anchor for the entire landing zone (another stent in RVOT).

For prestenting mainly bare metal stents were used in 36 patients. In 10 cases, patients with severe calcification CP covered stents were used as the initial stent. According to the literature significant and particularly circumferential homograft calcification is a risk factor for RV-PA conduit rupture and subsequent bleeding. The best way to avoid this often deadly complication is to use a covered stent. There were some patients with unfavorable PA anatomy (absent pulmonary valve with large main pulmonary artery, and absent left or right PA). Although technically more demanding, TPVR in these patients was successful. Chessa et al. [22] reported valve implantation in the lumen of a single PA with this anatomy. This modification was not made, as these patients had a full homograft implanted and the TPVR procedure was performed in a standard manner. One significant complication was noted in this group of patients - stent migration was subsequently secured in the peripheral RPA branch.

TPVR may also be very useful in patients after failed surgical PA valve replacement. In the present study 2 patients had biological valves (stentless Freestyle 23 and core-matrix valve). In the first patient, one and half years after surgery, the gradient had increased to $49 \mathrm{~mm} \mathrm{Hg}$ and in the second patient to $52 \mathrm{~mm} \mathrm{Hg}$. One stent was applied in a prestenting procedure in 1 patient and 2 stents in the second patient. In both cases a Melody valve was implanted with no complications and a good final result. TPVR not only prevents RV volume overload by establishing a barrier for flow reversal but, it also diminishes homograft narrowing and RV pressure. Significant gradient reduction was expected and observed particularly in patients with predominant stenosis. In all patients, pulmonary regurgitation was reduced to none or minor after the procedure - similarly to reported in literature $[5,7,8,14]$. To date, follow-up of this study ranges from 2 to 86 months. There was a $100 \%$ survival rate over this time. In only 1 patient, an increase in the implanted valve gradient was recorded in transthoracic echocardiography. No increase of implanted pulmonary valve regurgitation was observed in follow-up, indicating good function over this period of time. Usually, valve dysfunction in the short term is caused by infective endocarditis. Despite an increasing number of publications concerning this problem, no such complications were observed [23-25]. However, similar to the literature, there were 6 cases of broken stents 5 stents used for prestenting ( 1 covered CP stent, 1 AndraStent and 3 bare $\mathrm{CP}$ stents) and 1 stent used as Melody valve scaffolding. In two of those cases stent desintegration defragmentation was found, with part of the stent fixed to the peripheral PA branch. In both cases no significant valve dysfunc- 
tion was noted, although one had a peak gradient $80 \mathrm{~mm} \mathrm{Hg}$, and was qualified for percutaneous revalvulation. The number of "silent" stent fractures in this series is similar to literature $[9,17,19]$. In this experience some patients had fluoroscopy and some chest XR to look for fractures - the reason was a difference in follow-up protocol at the two centers. However Butera et al. [17] recommends fluoroscopy as a better tool to discover silent stent fractures - and yearly exams should be done. The risk factors for fractures are well known; implantation in a native narrowed RVOT, lack of calcifications and homograft recoil $[17,19,26]$. The best known way to avoid the problem is prestenting with multiple stents. In the present study there were 2 patients who had recoil in homograft narrowing. One patient required the implantation of 3 stents prior to completing the TPVR procedure, another patient received an additional third stent, 3 months after the initial prestenting. In the case of severe dysfunction of the previously implanted valve, according to some authors, patients may be treated with percutaneous revalvulation, and in others, surgery may be necessary.

\section{Limitation of the study}

The group of patients was collected from two centers with some differences in implantation details and follow-up protocols. Although most of the patients had Melody valves implanted, two received Edwards valves. The material and construction of the different valves renders the group of patients not homogeneous.

\section{Conclusions}

Patients with indication for percutaneous pulmonary valve implantation require careful RVOT assessment and sometimes, prestenting with multiple stents. TPVR was a safe procedure, with encouraging short- and mid-term results; avoiding the need for additional surgery.

\section{Conflict of interest: None declared}

\section{References}

1. Davlouros PA, Karatza AA, Gatzoulis MA, et al. Timing and type of surgery for severe pulmonary regurgitation after repair of tetralogy of Fallot. Int J Cardiol. 2004; 97 Suppl 1: 91-101, doi: 10.1016/j.ijcard.2004.08.013, indexed in Pubmed: 15590085.

2. Bonhoeffer P, Boudjemline Y, Qureshi SA, et al. Percutaneous insertion of the pulmonary valve. J Am Coll Cardiol. 2002; 39(10): 1664-1669, indexed in Pubmed: 12020495.
3. Oosterhof T, van Straten A, Vliegen HW, et al. Preoperative thresholds for pulmonary valve replacement in patients with corrected tetralogy of Fallot using cardiovascular magnetic resonance. Circulation. 2007; 116(5): 545-551, doi: 10.1161/CIRCULATIONAHA.106.659664, indexed in Pubmed: 17620511.

4. Bonhoeffer P, Boudjemline Y, Saliba Z, et al. Percutaneous replacement of pulmonary valve in a right-ventricle to pulmonaryartery prosthetic conduit with valve dysfunction. Lancet. 2000; 356(9239): 1403-1405, doi: 10.1016/S0140-6736(00)02844-0, indexed in Pubmed: 11052583.

5. Godart F, Baruteau AE, Petit J, et al. Transcatheter tricuspid valve implantation: a multicentre French study. Arch Cardiovasc Dis. 2014; 107(11): 583-591, doi: 10.1016/j.acvd.2014.07.051, indexed in Pubmed: 25282331.

6. Cullen MW, Cabalka AK, Alli OO, et al. Transvenous, antegrade Melody valve-in-valve implantation for bioprosthetic mitral and tricuspid valve dysfunction: a case series in children and adults. JACC Cardiovasc Interv. 2013; 6(6): 598-605, doi: 10.1016/j. jcin.2013.02.010, indexed in Pubmed: 23683739.

7. Hascoët S, Acar P, Boudjemline Y. Transcatheter pulmonary valvulation: current indications and available devices. Arch Cardiovasc Dis. 2014; 107(11): 625-634, doi: 10.1016/j. acvd.2014.07.048, indexed in Pubmed: 25444020.

8. Suradi HS, Hijazi ZM. Percutaneous pulmonary valve implantation. Glob Cardiol Sci Pract. 2015; 2015(2): 23, doi: 10.5339/ gcsp.2015.23, indexed in Pubmed: 26535223.

9. Ruzyłło W, Demkow M, Włodarska EK, et al. [POL-PAVTI--Polish report on transcatheter pulmonary artery valve implantation of Melody-Medtronic prosthesis in the first 14 patients in Poland]. Kardiol Pol. 2009; 67(10): 1155-1161, indexed in Pubmed: 20017086.

10. Armstrong AK, Balzer DT, Cabalka AK, et al. One-year follow-up of the Melody transcatheter pulmonary valve multicenter postapproval study. JACC Cardiovasc Interv. 2014; 7(11): 1254-1262, doi: 10.1016/j.jcin.2014.08.002, indexed in Pubmed: 25459038.

11. Shimazaki Y, Blackstone EH, Kirklin JW. The natural history of isolated congenital pulmonary valve incompetence: surgical implications. Thorac Cardiovasc Surg. 1984; 32(4): 257-259, doi: 10.1055/s-2007-1023399, indexed in Pubmed: 6207619.

12. Davlouros PA, Karatza AA, Gatzoulis MA, et al. Timing and type of surgery for severe pulmonary regurgitation after repair of tetralogy of Fallot. Int J Cardiol. 2004; 97 Suppl 1: 91-101, doi: 10.1016/j.jijcard.2004.08.013, indexed in Pubmed: 15590085.

13. Khambadkone S, Coats L, Taylor A, et al. Percutaneous pulmonary valve implantation in humans: results in 59 consecutive patients. Circulation. 2005; 112(8): 1189-1197, doi: 10.1161/CIRCULATIONAHA.104.523266, indexed in Pubmed: 16103239.

14. Nordmeyer J, Coats L, Bonhoeffer P. Current experience with percutaneous pulmonary valve implantation. Semin Thorac Cardiovasc Surg. 2006; 18(2): 122-125, doi: 10.1053/j. semtcvs.2006.07.006, indexed in Pubmed: 17157232.

15. Lurz P, Coats L, Khambadkone S, et al. Percutaneous pulmonary valve implantation: impact of evolving technology and learning curve on clinical outcome. Circulation. 2008; 117(15): 19641972, doi: 10.1161/CIRCULATIONAHA.107.735779, indexed in Pubmed: 18391109.

16. Sridharan S, Coats L, Khambadkone S, et al. Images in cardiovascular medicine. Transcatheter right ventricular outflow tract intervention: the risk to the coronary circulation. Circulation. 2006; 113(25): e934-e935, doi: 10.1161/CIRCULATIONAHA.105.599514, indexed in Pubmed: 16801469. 
17. Butera G, Milanesi O, Spadoni I, et al. Melody transcatheter pulmonary valve implantation. Results from the registry of the Italian Society of Pediatric Cardiology. Catheter Cardiovasc Interv. 2013; 81(2): 310-316, doi: 10.1002/ccd.24518, indexed in Pubmed: 22718682.

18. Morray BH, McElhinney DB, Cheatham JP, et al. Risk of coronary artery compression among patients referred for transcatheter pulmonary valve implantation: a multicenter experience. Circ Cardiovasc Interv. 2013; 6(5): 535-542, doi: 10.1161/CIRCINTERVENTIONS.113.000202, indexed in Pubmed: 24065444.

19. Cardoso R, Ansari M, Garcia D, et al. Prestenting for prevention of melody valve stent fractures: A systematic review and meta-analysis. Catheter Cardiovasc Interv. 2016; 87(3): 534-539, doi: 10.1002/ccd.26235, indexed in Pubmed: 26481871.

20. Cosentino D, Quail MA, Pennati G, et al. Geometrical and stress analysis of factors associated with stent fracture after melody percutaneous pulmonary valve implantation. Circ Cardiovasc Interv. 2014; 7(4): 510-517, doi: 10.1161/CIRCINTERVENTIONS.113.000631, indexed in Pubmed: 25097201.

21. Boshoff DE, Cools BLM, Heying R, et al. Off-label use of percutaneous pulmonary valved stents in the right ventricular outflow tract: time to rewrite the label? Catheter Cardiovasc Interv. 2013; 81(6): 987-995, doi: 10.1002/ccd.24594, indexed in Pubmed: 22887796 .
22. Chessa M, Butera G, Giugno L, et al. Percutaneous pulmonary valve implantation in a single artery branch: A preliminary experience. World J Cardiol. 2015; 7(10): 695-699, doi: 10.4330/wjc. v7.i10.695, indexed in Pubmed: 26516424.

23. Patel M, Malekzadeh-Milani S, Ladouceur M, et al. Percutaneous pulmonary valve endocarditis: incidence, prevention and management. Arch Cardiovasc Dis. 2014; 107(11): 615-624, doi: 10.1016/j.acvd.2014.07.052, indexed in Pubmed: 25445753.

24. Van Dijck I, Budts W, Cools B, et al. Infective endocarditis of a transcatheter pulmonary valve in comparison with surgical implants. Heart. 2015; 101(10): 788-793, doi: 10.1136/ /heartjnl-2014-306761, indexed in Pubmed: 25539944.

25. Buber J, Bergersen L, Lock JE, et al. Bloodstream infections occurring in patients with percutaneously implanted bioprosthetic pulmonary valve: a single-center experience. Circ Cardiovasc Interv. 2013; 6(3): 301-310, doi: 10.1161/CIRCINTERVENTIONS.112.000348, indexed in Pubmed: 23756696.

26. Gillespie MJ, Rome JJ, Levi DS, et al. Melody valve implant within failed bioprosthetic valves in the pulmonary position: a multicenter experience. Circ Cardiovasc Interv. 2012; 5(6): 862-870, doi: 10.1161/CIRCINTERVENTIONS.112.972216, indexed in Pubmed: 23212395. 